\title{
Intraepithelial Leukocytes of the Intestinal Mucosa in Normal Man and in Whipple's Disease A Light- and Electron-Microscopic Study
}

\author{
LINDA LEE AUSTIN, BA, and WILLIAM O. DOBBINS, III, MD
}

\begin{abstract}
Intraepithelial lymphocytes (IEL) of the intestinal mucosa of normal man and of patients with Whipple's disease were studied by light microscopy of 1 - $\mu$ m-thick sections, and by electron microscopy of thin sections. IEL in normal human intestine tend to be elongated in outline, have few cytoplasmic organelles, have compact nuclei, and are unattached to epithelial cells. IEL in Whipple's disease are more likely to be activated in appearance, ie, to be larger and to contain more cytoplasmic organelles than IEL of normal intestine. The number of IEL/100 intestinal epithelial cells is similar in normal man and in patients with Whipple's disease. Other intraepithelial (IE) cells found in normal intestine include eosinophils and mast cells, and we note for the first time the presence of IE macrophages. There are no "globule leukocytes" in the intestine of normal man or of patients with Whipple's disease. Other IE cells found in the intestine in Whipple's disease include eosinophils, polymorphonuclear (PMN) leukocytes, and macrophages in untreated disease and intraepithelial macrophages in treated disease. These IE cells may be involved in the acute and chronic immune responses of the intestine.
\end{abstract}

A close interaction of lymphocytes, epithelium, and antigens results from the unique anatomical arrangement of the gut (1). The role, if any, of the intraepithelial lymphocyte (IEL) in mucosal immunity is still being defined. While there are modest amounts of light-microscopic data concerning intraepithelial lymphocytes (IEL) in man (2-6), there are few electron-microscopic (EM) descriptions of the IEL in man (7-9). The appearance and distribu-

Manuscript received January 2, 1981; revised manuscript received March 25, 1981; accepted March 26, 1981.

From the Veterans Administration Medical Center, Ann Arbor, Michigan; and Department of Internal Medicine, Division of Gastroenterology, University of Michigan Medical Center.

Supported by Merit Review Funding from Veterans Administration Central Office, Washington, D.C.

Address for reprint requests: Dr. William O. Dobbins, III, Veterans Administration Medical Center, 2215 Fuller Road; Ann Arbor, Michigan 48105. tion of intraepithelial cells may have functional implications as to the pathogenesis of the presumed immunodeficiency in Whipple's disease (10). In particular, it is important to determine whether the intraepithelial compartment functions independently from the lamina propria compartment in mucosal immunity. In this report, we provide semiquantitative data in regard to light microscopy and EM of intraepithelial cells in normal man and report for the first time a survey of these cells in Whipple's disease. The presence of intraepithelial macrophages in the intestine of both normal man and patients with Whipple's disease is documented, and their possible functional role is suggested.

\section{MATERIALS AND METHODS}

Available for our review were 35 intestinal biopsies obtained from 12 patients with Whipple's disease. Seventeen biopsies were obtained from 10 patients prior to 
antibiotic treatment, and 18 biopsies were obtained from 5 patients after antibiotic treatment. All biopsies were obtained perorally at the duodenal-jejunal junction after an overnight fast. For control observations, 29 normal intestinal biopsies obtained from 28 individuals, in whom diffuse intestinal disease was excluded, were available for survey.

All biopsies were processed for light and electron microscopy according to standard methods (11). Two to four sections $1 \mu \mathrm{m}$ thick were prepared from each of the blocks for light microscopy, and thin sections were collected on carbon-coated copper grids and routinely stained for electron microscopy (11). Particular care was given to obtaining sections parallel to villi so that the entire length of villi, including crypts of Lieberkuhn, were included in each thin section. Electron micrographs were obtained during the past 15 years in the performance of a large number of electron-microscopic studies of the intestinal mucosa (11). Thus, the observations in regard to the intraepithelial lymphocytes were random, permitting a semiquantitative analysis of the cells as seen at electron microscopy.

Observations were recorded for all intraepithelial cells, but only lymphocytes were analyzed quantitatively. Intraepithelial cells are defined as nonepithelial cells found above the epithelial basal lamina and between epithelial cells, ie, within the epithelium. Observations were made only on lymphocytes that appeared to have been transsected in their center and which contained an intact nucleus. Lymphocyte size was determined by measuring length and width of the cell, and nuclear size was determined similarly. Even though lymphocytes appear to be round at light microscopy (hence requiring a single measurement of diameter), IEL are generally elongated at EM and thus measures of length and width are necessary. The relationship of lymphocytes to epithelial cell nuclei (above, below, or at the level of nuclei) and the presence or absence of a Golgi apparatus and of centrioles were determined. The appearance, width, and number of mitochondria in each lymphocyte were recorded. The number of lysosomes per lymphocyte was recorded. The lysosomes were considered to be large if they were clearly larger in size than mitochondria of the same cell and were considered to be small if they were smaller in size than the average cross-sectional diameter of mitochondria of that cell. The appearance of rough and smooth endoplasmic reticulum and of ribosomes, isolated or polyribosomal, was recorded.

As a rough estimate of the number of lymphocytes in relation to epithelial cells, all epithelial cells were counted in electron micrographs containing intraepithelial lymphocytes. In order to have a more accurate estimate of the number of lymphocytes per epithelial cell, each thick section was examined at light microscopy (oil immersion, $\times 1000$ ) and the number of IEL and epithelial cells (goblet cells excluded) was determined. Counts were obtained only in those areas in which all of the epithelial cells appeared to be sectioned parallel to their entire length and in which none of the cells were tangentially sectioned (2): Areas in which there appeared to be trauma were not counted. Observations of "normal controls" were made only in biopsies obtained from patients without diffuse intestinal disease. A number of proximal duodenal biopsies which were clearly normal in appearance were available for our review. These biopsies had been obtained from patients without diffuse intestinal disease and were morphologically normal in appearance. Because the proximal duodenum is subject to varying amounts of "physiological" inflammation, particularly when compared to the distal duodenum, we analyzed separately the number of intraepithelial lymphocytes in proximal duodenum of 12 normal individuals and in distal duodenum of 16 normal individuals.

Lymphocytes are defined as small, medium, or large. Small lymphocytes tend to be less than $5.5 \mu \mathrm{m}$ in diameter and contain scanty mitochondria, single ribosomes, sparse endoplasmic reticulum, and a small rim of cytoplasm about a compact heterochromatic nucleus. Medium sized lymphocytes are 5-9 $\mu \mathrm{m}$ in diameter, contain small lysosomes, well-developed Golgi complexes, and occasional centrioles. Large lymphocytes are larger than $9 \mu \mathrm{m}$ in diameter and have a large euchromatic nucleus with prominent nucleoli (12). Lymphocytes do not form junctional complexes with adjacent epithelial cells.

Intraepithelial macrophages are as large or larger than lymphoblasts and contain a small indented nucleus with abundant cytoplasm. There are numerous cytoplasmic organelles, many of which are dense bodies (presumably lysosomes when appropriately stained with acid phosphatase). The cytoplasm of macrophages at the edge of the cell and within pseudopods is generally organelle-free and contains numerous pinocytic vesicles (13). Possibly the simplest definition of the macrophage is that of a medium or large nonepithelial mononuclear cell that exhibits evidence of actual or potential phagocytic activity (13). There is no easy distinction of monocytes from young macrophages, and one may confuse monocytes with occasional large lymphocytes. The morphological characteristics of lymphocytes, monocytes, and macrophages are such that ordinarily there is little difficulty distinguishing the cells at electron microscopy. Other intraepithelial cells identified (eosinophils, mast cells, plasma cells, and polymorphonuclear leukocytes) are easily distinguished by standard morphological criteria.

\section{RESULTS}

Normal Intestine. Sixty-one IELs in normal proximal intestine and 81 IELs in normal distal intestine were analyzed at electron microscopy (Tables 1 and 2, Figure 1). Portions of 56 IELs ( 20 proximal and 36 distal) were observed but were not quantitated because they did not appear to be sectioned in their center. Mitochondrial diameter was less than 0.5 $\mu \mathrm{m}$ in $90 \%$ and did not exceed $0.7 \mu \mathrm{m}$. The content of small lysosomes is shown in Table 2 . The term "lysosome" refers to membrane-enclosed homogeneous and heterogeneous dense bodies that presumably contain acid phosphatases. A specialized form of the lysosome, the multivesicular body, was observed in two of the proximal cells and 11 of the 


\section{INTRAEPITHELIAL CELLS IN WHIPPLE'S DISEASE}

Table 1. Quantitative Features of Intraepithelial Lymphocytes in Normal and Whipple InTEstinal Mucosa Determined at Electron Microscopy (EM) and Light Microscopy (LM)

\begin{tabular}{|c|c|c|c|c|}
\hline & \multicolumn{2}{|c|}{ Normal } & \multicolumn{2}{|c|}{ Whipple's } \\
\hline & Proximal & Distal & Treated & Untreated \\
\hline Lymphocytes quantitated (EM) & 61 & 81 & 12 & 74 \\
\hline Partial lymphocytes observed (EM) & 20 & 36 & 3 & 56 \\
\hline Cells containing a Golgi apparatus (EM) & $13(21 \%)$ & $9(11 \%)$ & $3(25 \%)$ & $13(18 \%)$ \\
\hline \multicolumn{5}{|l|}{ Mitochondria/cell (EM } \\
\hline Mean & 4.3 & 4.1 & 2.6 & 4.9 \\
\hline Range & $0-15$ & $0-17$ & $0-7$ & $0-18$ \\
\hline Cells without & 7 & 21 & 2 & 20 \\
\hline Cells containing centriole (EM) & 5 & 3 & 1 & 5 \\
\hline \multicolumn{5}{|l|}{ Location of lymphocytes (LM) } \\
\hline Below epithelial nuclei & $276(60 \%)$ & $611(61 \%)$ & $198(60 \%)$ & $253(54 \%)$ \\
\hline At epithelial nuclei & $100(22 \%)$ & $236(24 \%)$ & $79(24 \%)$ & $128(28 \%)$ \\
\hline Above epithelial nuclei & $81(18 \%)$ & $151(15 \%)$ & $53(16 \%)$ & $85(18 \%)$ \\
\hline \multicolumn{5}{|l|}{ Number of lymphocytes $/ 100$ epithelial cells } \\
\hline Electron microscopy (mean) & 12.5 & 15 & 11 & 15 \\
\hline Light microscopy (mean \pm SD) & $14 \pm 9$ & $20.5 \pm 10$ & $22.7 \pm 3.8$ & $19 \pm 10.5$ \\
\hline
\end{tabular}

distal cells. The lysosomes were predominantly homogeneous, and only two large lysosomes (minimally larger than the mitochondrial cross-section) were observed in the total of 142 lymphocytes normally sectioned. Endoplasmic reticulum, graded on a scale of $1+$ to $4+$, was present in all except four proximal cells and all except 11 distal cells. The rough-surfaced variety predominated over the smooth-surfaced variety by a ratio of $2: 1$. The amount was usually $1+$ or less and was never more prominent than $2+$. Ribosomes were present in all lymphocytes and were equally divided between the isolated variety and the polyribosomal variety. The ribosomal content was judged to be $1+$ (on a scale of 1 to 4) or less in three fourths of the cells and 2+ in the remaining one fourth of the cells.

The location of IEL in relation to epithelial nuclei is shown in Table 1. In the electron micrographs containing normally sectioned lymphocytes, there were 12.5 lymphocytes/ 100 proximal epithelial cells and 15 lymphocytes $/ 100$ distal epithelial cells. A more accurate measure of lymphocyte density was obtained at light microscopy which showed $14 \pm 9$ (mean \pm standard deviation) lymphocytes/100 proximal epithelial cells (3289 epithelial cells counted) and $20.5 \pm 10$ lymphocytes/100 distal epithelial cells (4870 epithelial cells counted).

Figure 2 shows size of the normal lymphocytes expressed in terms of surface area, while Figure 3 shows nuclear size. Nuclei were generally compact, occasionally irregular in outline, and contained prominent amounts of heterochromatin. Nucleoli were present. Special care was taken to avoid confusing a tangentially sectioned enteroendocrine (EE) cell with an IEL. EE cells are found at the base of the crypts with their nuclei generally located below epithelial cell nuclei. EE cells have less dense cytoplasmic density than epithelial cells, contain numerous dense granules, and have desomosomal attachments to epithelial cells. We generally avoided this confusion by searching carefully for desmosomes of EE cells, an attachment device not found on lymphocytes. If there was doubt about the nature of a cell, it was not considered to be a lymphocyte. One apparent disintegrating "distal" lymphocyte was noted and one lymphocyte traversing the "proximal" epithelial basal lamina was observed (Figure 4). Lymphocytes were not ob-

Table 2. Lysosomal Characteristics of Normal LYMPHOCYTES*

\begin{tabular}{|c|c|c|c|c|}
\hline \multirow[b]{3}{*}{ Number/cell } & \multicolumn{4}{|c|}{ Number of cells } \\
\hline & \multicolumn{2}{|c|}{ Proximal } & \multicolumn{2}{|c|}{ Distal } \\
\hline & $\begin{array}{l}\text { Hetero- } \\
\text { geneous }\end{array}$ & $\begin{array}{l}\text { Homo- } \\
\text { geneous }\end{array}$ & $\begin{array}{l}\text { Hetero- } \\
\text { geneous }\end{array}$ & $\begin{array}{l}\text { Homo- } \\
\text { geneous }\end{array}$ \\
\hline $1-5$ & 4 & 18 & 5 & 25 \\
\hline $6-10$ & 0 & 1 & 0 & 1 \\
\hline$>10$ & 0 & 0 & 0 & 1 \\
\hline Range/cell & $0-4$ & $0-10$ & $0-3$ & $0-15$ \\
\hline $\begin{array}{c}\text { Cells without } \\
\text { lysosomes }\end{array}$ & \multicolumn{2}{|c|}{$38 / 61(62 \%)$} & \multicolumn{2}{|c|}{$48 / 81(60 \%)$} \\
\hline
\end{tabular}

* Range of small heterogeneous and homogeneous dense bodies (presumably lysosomes) observed per intraepithelial lymphocyte sectioned normally (142 cells) in intestinal biopsies of normal individuals. 


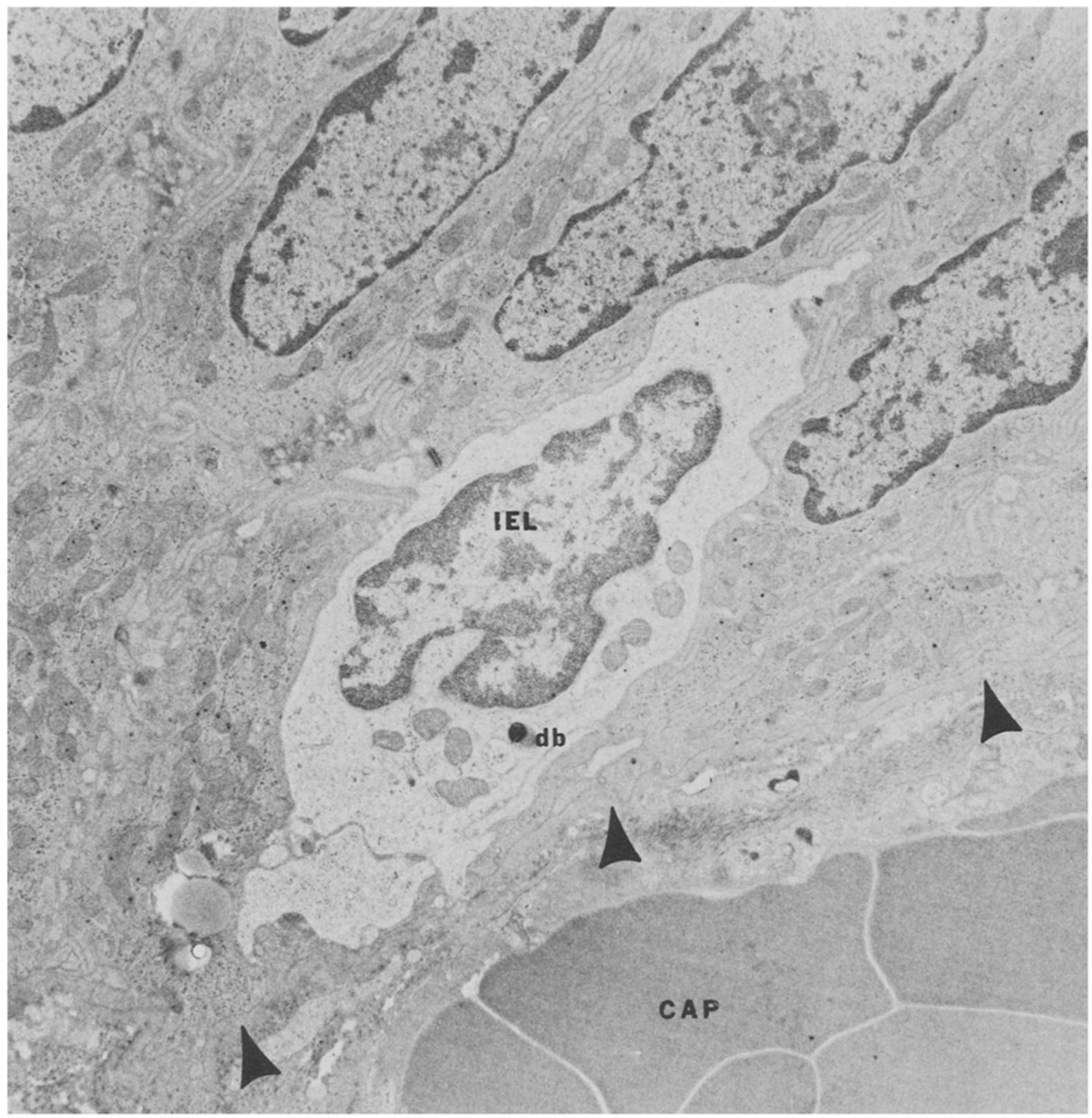

Fig 1. Electron micrograph illustrating appearance of typical IEL in normal proximal duodenum. The IEL is at the base of epithelial cells, is elongated, and contains sparse mitochondria, little endoplasmic reticulum, and a multivesicular body adjacent to a small heterogeneous dense body $(\mathrm{db})$. The cytoplasm is less dense than that of adjacent cells and the nucleus contains modest amounts of heterochromatin. The epithelial basal lamina is outlined by arrows. Blood capillary (CAP). $\times 10,600$.

served traversing the luminal junctional complex of epithelial cells, nor were they observed within the gut lumen. There were no epithelial plasma cells.

Other intraepithelial cells observed included four monocytes, four eosinophils, one mast cell, and two macrophages in the distal intestine, and one monocyte, eight eosinophils, and two mast cells in the proximal intestine. Epithelial cell invasion by intraepithelial cells similar to that seen by PMN leukocytes in the colon in ulcerative colitis was not observed (14). There were no attachment devices between any of the intraepithelial cells and epithelial cells.

Whipple's Disease. Seventy-four IELs in biopsies 


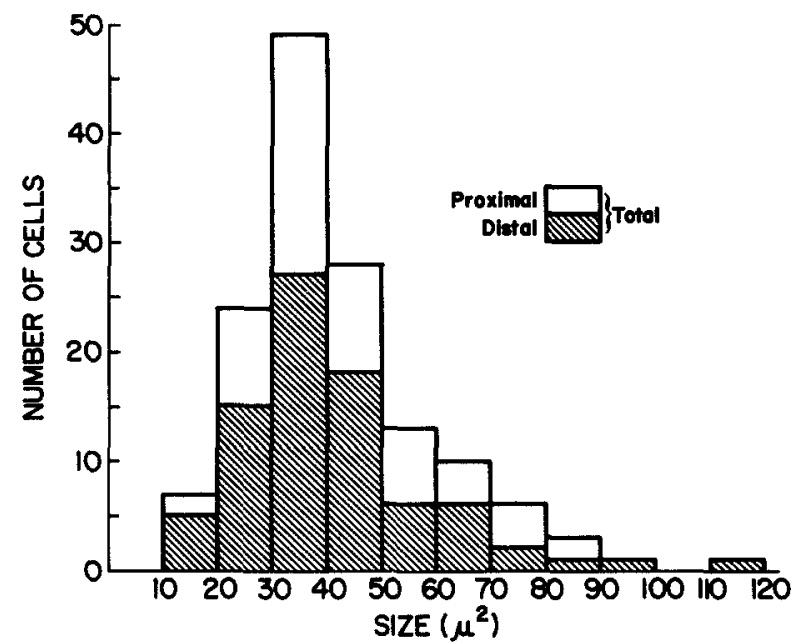

Fig 2. Diagrammatic representation of size of normally sectioned intraepithelial lymphocytes (142) in normal proximal and distal duodenal biopsies expressed as square microns (length times width).

obtained from untreated patients and 12 IELs in biopsies obtained from treated patients were analyzed at electron microscopy. Portions of 59 IELs (three in treated and 56 in untreated patients) were observed but not quantitated (Table 1). The content of small lysosomes is shown in Table 3. Multivesicular bodies were observed in nine of the "untreated" lymphocytes and in none of the "treated." The lysosomes were predominantly homogeneous, and only five of the untreated lymphocytes contained lysosomes which were slightly larger than the crosssectional diameter of mitochondria (similar in size to mitochondria of IEL of normal mucosa). Endoplasmic reticulum was present in seven of the treated lymphocytes and in 50 of the untreated lymphocytes. There was a $2: 1$ ratio of the roughsurfaced variety to the smooth-surfaced variety. The amount of endoplasmic reticulum was always $1+$ or less. Ribosomes were present in all lymphocytes and were equally divided between the isolated variety and the polyribosomal variety. The content of ribosomes was generally $1+$ or less; two of the treated lymphocytes and 18 of the untreated lymphocytes contained a $2+$, and four of the "untreated" lymphocytes contained a $3+$ ribosomal content. There were no distinguishing features of the lymphocyte nuclei. The location of the IELs in relation to epithelial nuclei is shown in Table 1. In electron micrographs containing normally sectioned lymphocytes, there were 11 lymphocytes/100 treat-

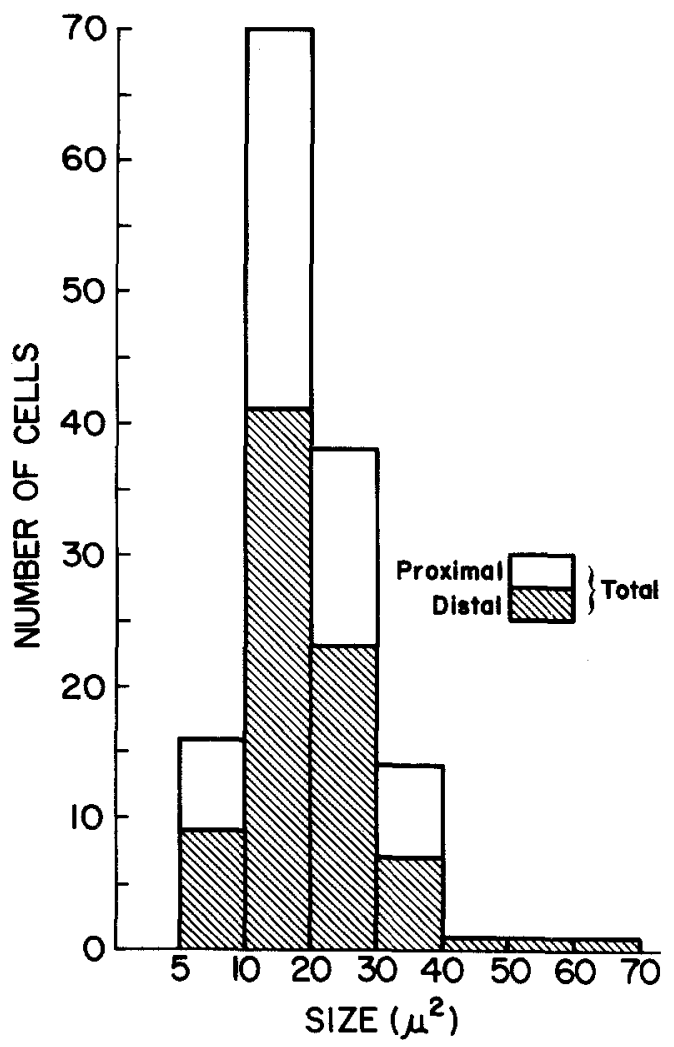

Fig 3. Diagrammatic representation of nuclear size, in square microns, of the cells in Figure 2.

ed epithelial cells and 15 lymphocytes/100 untreated epithelial cells. The more accurate light-microscopic analysis of lymphocyte density showed $22.7 \pm$ 3.8 lymphocytes $/ 100$ treated epithelial cells $(1702$

Table 3. Lysosomal Characteristics of Whipple LYMPHOCYTES*

\begin{tabular}{|c|c|c|c|c|}
\hline \multirow[b]{3}{*}{ Number/cell } & \multicolumn{4}{|c|}{ Number of cells } \\
\hline & \multicolumn{2}{|c|}{ Treated } & \multicolumn{2}{|c|}{ Untreated } \\
\hline & $\begin{array}{l}\text { Hetero- } \\
\text { geneous }\end{array}$ & $\begin{array}{l}\text { Homo- } \\
\text { geneous }\end{array}$ & $\begin{array}{l}\text { Hetero- } \\
\text { geneous }\end{array}$ & $\begin{array}{l}\text { Homo- } \\
\text { geneous }\end{array}$ \\
\hline $1-5$ & 3 & 2 & 4 & 30 \\
\hline $6-10$ & 0 & 0 & 0 & 4 \\
\hline 10 & 0 & 1 & 0 & 2 \\
\hline Range/cell & $0-2$ & $0-13$ & $0-3$ & $0-16$ \\
\hline $\begin{array}{l}\text { Cells without } \\
\text { lysosomes }\end{array}$ & \multicolumn{2}{|c|}{$8 / 12(67 \%)$} & \multicolumn{2}{|c|}{$36 / 74(49 \%)$} \\
\hline
\end{tabular}

* Range of small heterogeneous and homogeneous dense bodies (presumably lysosomes) observed per intraepithelial lymphocyte sectioned normally ( 86 cells) in intestinal biopsies of patients with Whipple's disease. 


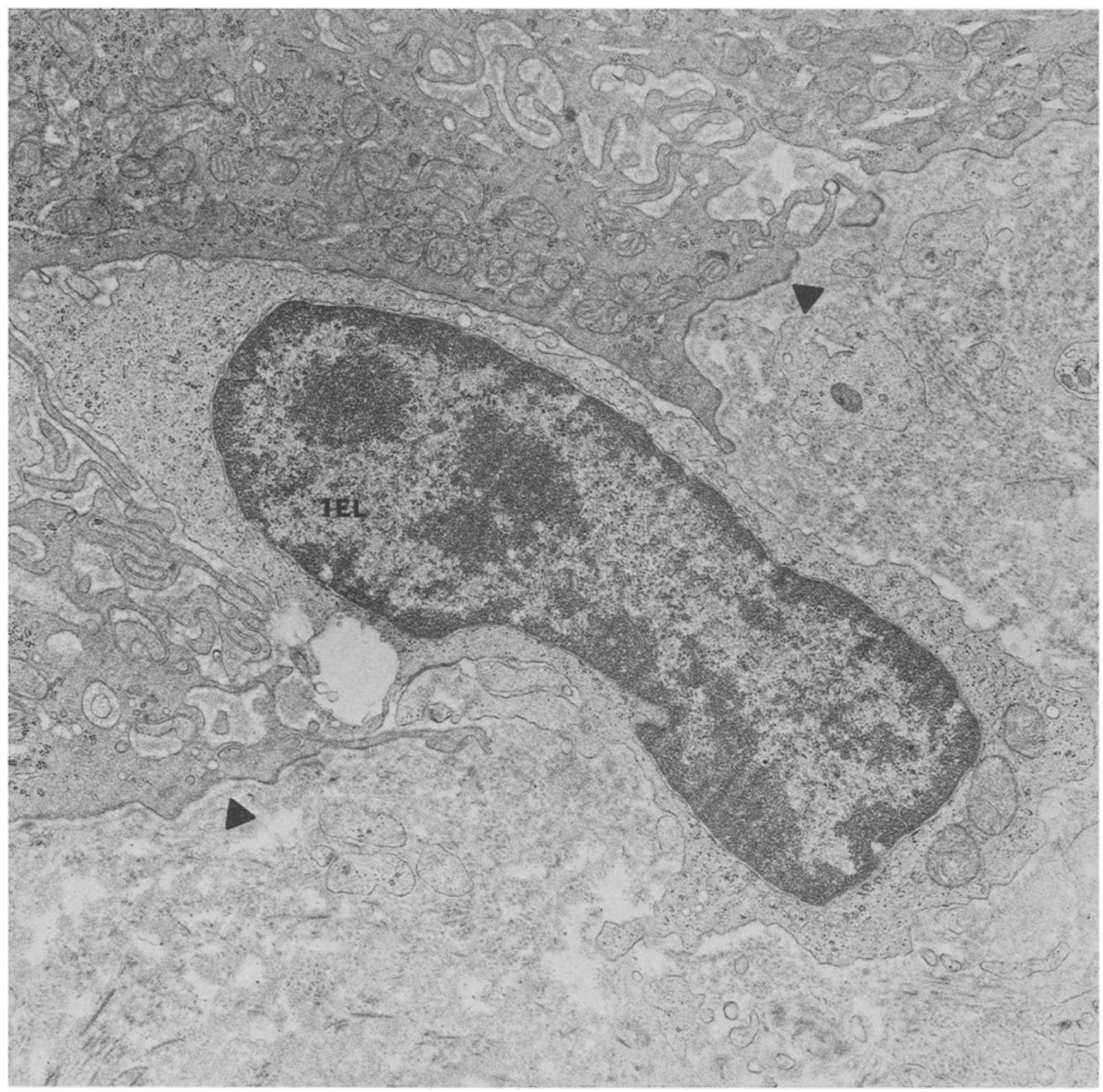

Fig 4. Electron micrograph illustrating lymphocyte traversing basal lamina in a normal proximal duodenal biopsy. It is likely that the intraepithelial portion of the lymphocyte represents the pseudopod or anterior end, while the mitochondria-containing portion is the uropod or posterior portion (20), but this cannot be determined with certainty. Arrows outline the epithelial basal lamina. $\times 14,600$.

epithelial cells counted) and $19 \pm 10.5$ lymphocytes/100 untreated epithelial cells (2389 epithelial cells counted). Figure 5 shows size of the lymphocytes expressed in terms of surface area; Figure 6 shows nuclear size. No disintegrating lymphocytes were observed, and no evidence of lymphocytes traversing the luminal junctional complex of epithelial cells was detected. Lymphocytes were not observed in the gut lumen. Intraepithelial plasma cells were not seen.

Other intraepithelial cells identified included 13 macrophage/monocytes (Figure 7) and one PMN leukocyte in treated intestine and 7 eosinophils, 4 macrophage/monocytes, and 29 PMN leukocytes in the untreated intestine. There was no evidence of PMN leukocyte invasion of epithelial cells. On two 


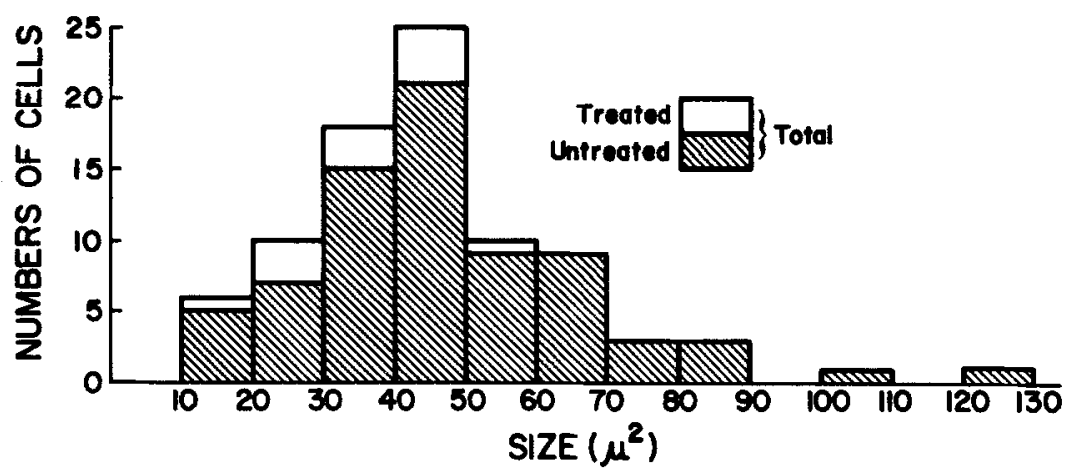

Fig 5. Diagrammatic representation of size of normally sectioned intraepithelial lymphocytes found in duodenal biopsies of patients with treated and untreated Whipple's disease expressed as square microns (length times width).

occasions, macrophages were noted apparently traversing the epithelial basal lamina (Figure 7). Bacterial uptake by intraepithelial PMN leukocytes and lymphocytes was present in untreated biopsies (15).

\section{DISCUSSION}

We have confirmed the observations of Toner and Ferguson in regard to EM features of IEL in human small intestine (7). These cells tend to be elongated in outline, contain sparse cytoplasmic organelles, have compact nuclei, and are unattached to adjacent epithelial cells. Care must be taken to avoid confusion of IELs with tangentially sectioned enteroendocrine cells containing few granules. Dense granules in human IEL are small and probably represent lysosomes. Confirming oth-

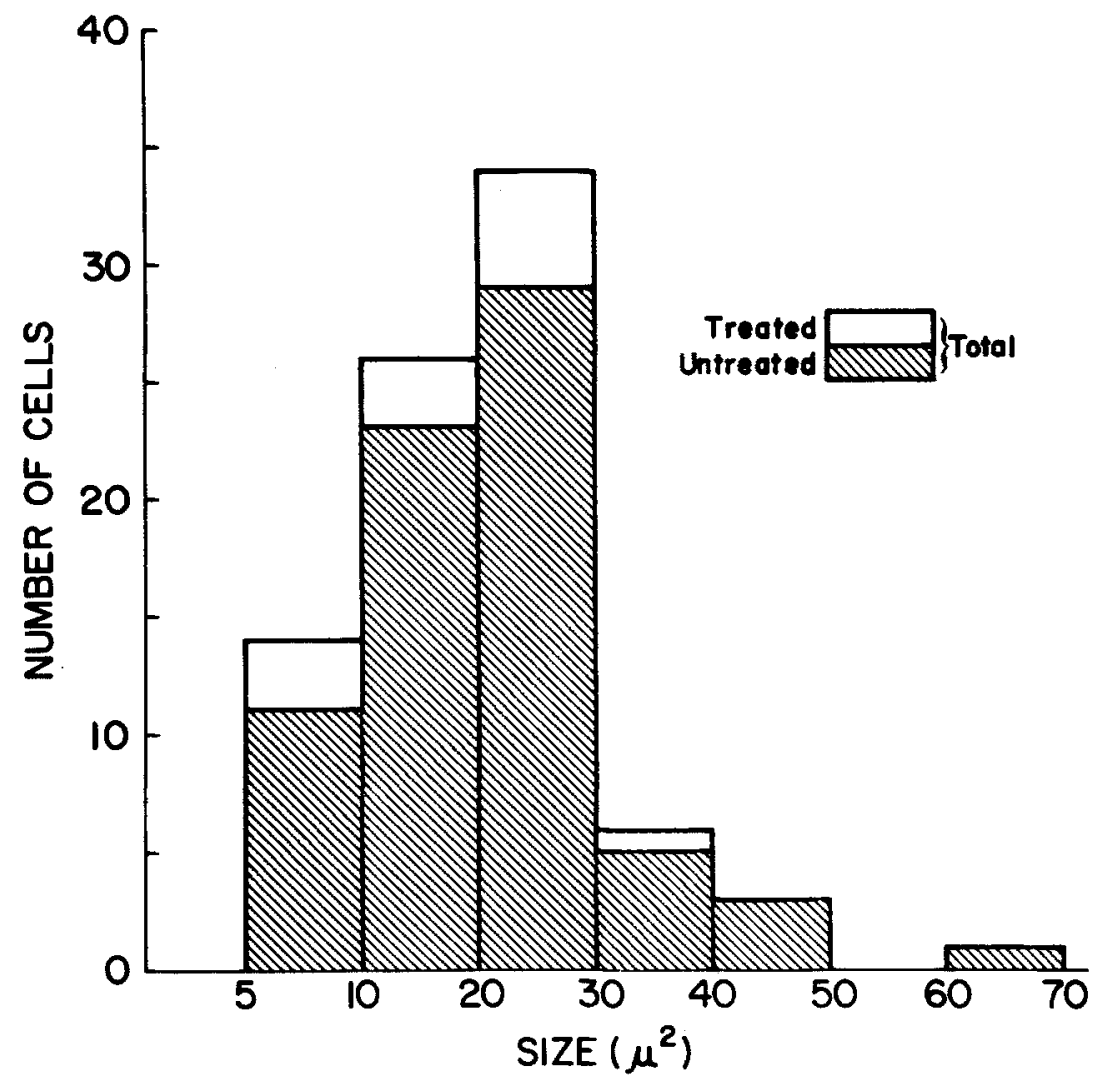

Fig 6. Diagrammatic representation of nuclear size, in square microns, of the cells in Figure 5. 


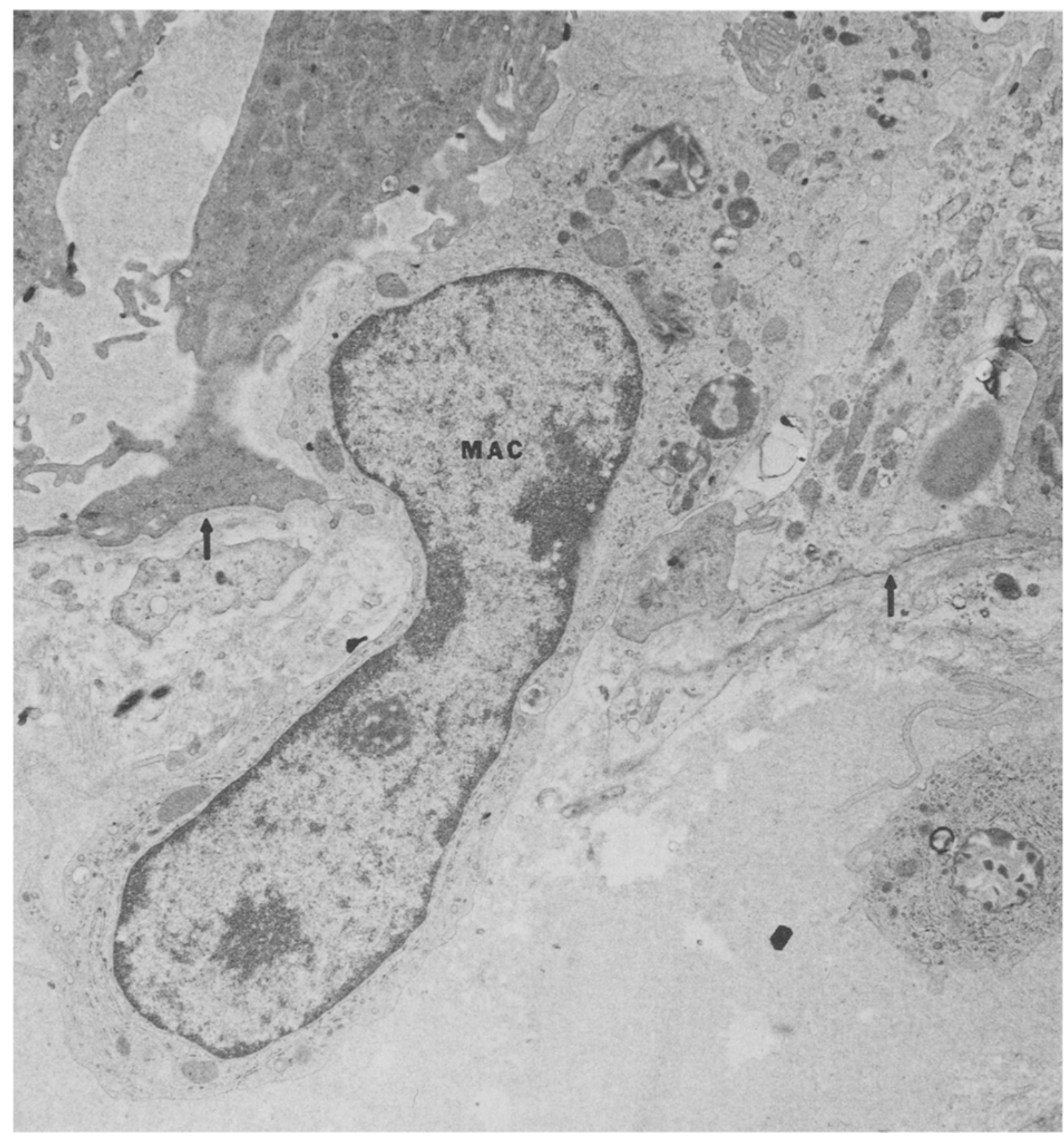

Fig 7. Electron micrograph illustrating macrophage (MAC) traversing epithelial basal lamina (arrows) of duodenal biopsy of a patient with untreated Whipple's disease. Note the numerous inclusions containing remnants of ingested bacilli. $\times 10,600$.

er observations, we did not see large granulecontaining lymphocytes comparable to so-called globule leukocytes of small animals (3, 7-9). There were fewer IELs per 100 epithelial cells in the proximal duodenum than in the distal duodenum; this is in accord with Otto's observation that IEL density increases from duodenum to ileum (3).
Ferguson reported a mean of 21.1 and a standard deviation of 7.5 lymphocytes per 100 epithelial cells in normal intestine (5), while we observed a mean of 17.5 and a standard deviation of 9.9 in normal proximal and distal duodenum (data combined). IELs are occasionally seen spanning the epithelial basal lamina. Intraepithelial eosinophils and mast 
cells have also been described by others $(3,7)$, and we report the presence of small-intestinal intraepithelial monocytes and macrophages in man. IEL macrophages have beeen noted in small animals (16). In view of the requirement for macrophages in the normal immune response (17), and in view of some evidence that IELs may play a role in mucosal immunity $(1,12)$, the presence of intraepithelial macrophages at least supports the possibility that the intraepithelial compartment could function independently from the lamina propria compartment in some aspects of immune function. Further, in a separate communication, we describe the presence of intraepithelial PMN leukocytes in Whipple's disease, some of which contained ingested Whipple bacilli (15), supporting the role of these cells in the acute inflammatory response.

We found no major differences in the range of fine structural appearance between IELs seen in patients with Whipple's disease and those seen in normal individuals. IELs in Whipple's disease were slightly larger in size, had slightly larger nuclei, were slightly more likely to contain lysosomes, and were more likely to have an increased content of ribosomes. The number of IEL/100 epithelial cells in normal intestine and in Whipple's intestine are similar, an observation also noted by Otto (3). Thus, the IELs may not be involved quantitatively in the immune response in Whipple's disease (10).

Marsh noted in the mouse that "of all the various cell types present within the lamina propria, it is remarkable that only lymphocytes predominantly gain access to the epithelium" (12). We found intraepithealial PMN leukocytes, eosinophils, and macrophages in untreated Whipple's disease and intraepithelial macrophages. Our observations indicate that, at least in Whipple's disease, there are in the epithelium a large number of other cells involved in the immune response. Now that methods are available for separating intraepithelial cells from lamina propria cells, the functional role (if any) of these cells can be explored (18). Further support confirming our morphologic observation of intraepithelial macrophages is noted in the finding of macrophages (as defined histochemically and functionally) in the intraepithelial collection from human colon (18).

One additional observation (data not included in Table 1) suggesting that IELs may have a role in mucosal immunity was made in our single patient with Whipple's disease in the absence of intestinal involvement (19). Intestinal biopsies in this patient revealed 75.6 IEL/100 epithelial cells (1113 epithelial cells counted). This single patient had four times the number of IEL in comparison to patients with untreated Whipple's disease with intestinal involvement.

\section{ACKNOWLEDGMENTS}

The authors are grateful to Dr. David Keren, who reviewed the manuscript and made many helpful suggestions, and to Dr. Robert L. Owen, who reviewed some of the electron micrographs and confirmed our observation of intraepithelial macrophages.

\section{REFERENCES}

1. De Sousa M, Good RA: T and B-cell populations in gut and gut-associated lymphoid organs: Arrangement, migration, and function. In Gastrointestinal Tract Cancer, M Lipkin, RA Good (eds). New York, Plenum Medical, 1978, pp 29-47

2. Ferguson A, Murray D: Quantitation of intraepithelial lymphocytes in human jejunum. Gut 12:988-994, 1971

3. Otto HF: The inter-epithelial lymphocytes of the intestine: Morphological observations and immunologic aspects of intestinal enteropathy. Curr Top Pathol 57:81-121, 1973

4. Shiner M, Ballard J, Smith ME: The small intestinal mucosa in cow's milk allergy. Lancet 1:136-140, 1975

5. Ferguson A: Progress report: Intraepithelial lymphocytes of the small intestine. Gut 18:921-937, 1977

6. Guix M, Skinner JM, Whitehead R: Measuring intraepithelial lymphocytes, surface area, and volume of lamina propria in the jejunal mucosa of celiac patients. Gut 20:275-278, 1978

7. Toner PG, Ferguson A: Intra-epithelial cells in the human intestinal mucosa. J Ultrastruct Res 34:329-344, 1971

8. Meader RD, Landers DF: Electron and light microscopic observations on relationships between lymphocytes and intestinal epithelium. Am J Anat 121:763-774, 1967

9. Orlic D, Lev R: An electron microscopic study of intraepithelial cells in human fetal small intestine. Lab Invest 37:554-561, 1977

10. Dobbins WO III: Is there an immune deficit in Whipple's disease? Dig Dis Sci 26:247-252, 1981

11. Dobbins WO III: Diagnostic pathology of the intestine and colon. In Diagnostic Electron Microscopy, Vol I, BF Trump, RT Jones (eds). New York, John Wiley \& Sons, 1978, pp 253-339

12. Marsh MN: Studies of intestinal lymphoid tissue I. Electron microscopic evidence of "blast transformation" in epithelial lymphocytes of mouse small intestinal mucosa. Gut 16:665674, 1975

13. LeFevre ME, Hammer R, Joel DD: Macrophages of the mammalian small intestine: A review. J Reticuloendothel Soc 26:553-573, 1979

14. Dobbins WO III: Colonic epithelial cells and polymorphonuclear leukocytes in ulcerative colitis. Am J Dig Dis 20:236252, 1975

15. Dobbins WO III, Kawanishi H: Bacillary characteristics in Whipple' disease. Gastroenterology 80:1468-1475, 1981 
16. Collan Y: Characteristics of nonepithelial cells in the epithelium of normal rat ileum. Scand J Gastroenterol 7(Suppl 18):1, 1972

17: Unanue ER: Cooperation between mononuclear phagocytes and lymphocytes in immunity. $\mathrm{N}$ Engl J Med 303:977-985, 1980

18. Bartnik W, ReMine SG, Chiba M, Thayer WR, Shorter RG: Isolation and characterization of colonic intraepithelial and lamina propria lymphocytes. Gastroenterology 78:976-985, 1980

19. Mansbach CM II, Shelburne RA, Stevens RD, Dobbins WO III: Lymph node bacilli-form bodies resembling those of Whipple's disease in a patient without intestinal involvement. Ann Intern Med 89:64-66, 1978

20. McFarland W, Schechter GP: The lymphocyte in immunological reactions in vitro: Ultrastructural studies. Blood $35: 686-688,1970$ 